\title{
Relationship between Thiamine Deficient Cardiac Lesions and Myocardial and Blood Pyruvic Acid Contents
}

\author{
Seizo Yamashita, M.D.
}

Summary

To study the correlation between thiamine deficient cardiac lesions and pyruvic acid contents, blood and organ pyruvic acid contents in normal, thiamine deficient and control pair fed rats were determined.

1) Pyruvic acid increased generally in thiamine deficient groups but did not in control pair fed groups.

2) In cases in which thiamine deficient symptoms were lacking, there were hardly any pyruvic acid increase.

3) Myocardial and blood pyruvic acid contents were markedly high and pyruvic acid ratio between heart muscle and blood was lowest in cardiac lesion groups, the severer the bradycardia and cardiac hypertropy the higher the myocardial and blood pyruvic acid contents, and myocardial pyruvic acid contents were especially high in ST elevation cases.

4) In thiamine deficient last stage cases, variations of pyruvic acid contents considered as agonal phenomena were observed.

5) The above results indicate that pyruvic acid accumulation in heart muscle and blood, especially in heart muscle, is the strong factor of thiamine deficient cardiac lesions.

\section{Additional Indexing Words :}

Thiamine deficiency Organ pyruvic acid contents

QINCE it had become known that pyruvic acid* oxidation is disturbed ${ }^{1)}$ $D$ and blood py contents increase ${ }^{2-5)}$ owing to thiamine deficiency, numerous studies concerning the relationship between thiamine and py metabolism have been carried on.

However, on the relationship between py increase and thiamine deficient symptoms there are two conflicting views that abnormal increase of blood py is the main cause of thiamine deficient symptoms and that there is no direct relation between py increase and thiamine deficient symptoms. And as yet no definite conclusion has been drawn. Tokyo

From the First Department of Internal Medicine, Faculty of Medicine, University of Tokyo,

Received for publication May 24, 1971

* Pyruvic acid is abbreviated py, the blood contents shown as $\mathrm{mg} / 100 \mathrm{ml}$. and the organ contents shown as $\mathrm{mg} . / 100 \mathrm{Gm}$. wet weight. 
The author has been carrying on studies on the etiological mechanism of thiamine deficient cardiac lesions. ${ }^{6)-10}$, This investigation was planned to study whether py increase had any connection with the etiology of thiamine deficient cardiac lesions or not.

\section{Materials and Methods}

1) Animals and feedings: Wistar strain young male rats were divided into 3 groups; normal, thiamine deficient and control pair fed groups. Each group was kept according to previously decided methods. ${ }^{61,7), 9\}}$

2) Electrocardiographic examination: On the progress of each group, electrocardiograms were at first recorded twice a week but daily at the final stage. ${ }^{6), 9 /, 11)}$

3) Blood collection: Cervical blood vessel was cut off at one stroke with surgical scissors under non-anesthetic condition and bleeding blood was quickly collected in a syringe. Besides the above methods, for studies of py determination and influence of anesthesia, blood was collected directly from abdominal vein with a syringe after laparotomy under anesthesia.

One ml. of the blood* was injected quickly into $5 \mathrm{ml}$. of ice-cold trichlor acetic acid and disproteined.

4) Tissue collection: Heart was excised right after blood collection, blood on it was wiped quickly with dry gauze and heart was frozen in acetone dry ice. Kidney and brain were also excised quickly and treated in the same way. For the study of brain mainly, blood collection was omitted, head was cut off at one stroke under non-anesthetic condition and frozen, and frozen brain was excised with a chisel.

Each frozen organ was weighed, $0.5-1.0 \mathrm{Gm}$. of it was put into Potter-Elvehjem type glass homogenizer containing $4 \mathrm{ml}$. of ice-cold trichlor acetic acid, homogenized at $1,500 \mathrm{rpm}$ for $4 \mathrm{~min}$. under ice-cold condition, the whole thing was immersed in boiling water for 4 min.**, cooled with ice, the contents poured into glass cylinder, contents stuck inside of homogenizer was washed with ice-cold trichlor acetic acid, and total volume of contents made accurately to $6 \mathrm{ml}$.

5) Determination: Disproteined blood and homogenized tissue were centrifuged at 3,000 rpm for $5 \mathrm{~min}$. and $4 \mathrm{ml}$. of supernatant was taken as determination samples. The procedure up to the stage of py hydrazone color reaction was done according to Friedemann-Haugen's method. ${ }^{13)}$ The determination was carried out by a photoelectric colorimeter using $440 \mathrm{~m} \mu$. wave length.

\section{RESULTS}

1) Py contents in organs of normal rats: Rats weighing 150-200 Gm. were used. In cases in which blood was collected under relatively quiet condi-

* One ml. is accurately marked beforehand on the syringe.

** From preliminary experiments of comparative determination of same organs and recovery tests adding py, it was found that exudation of py from the cells was better after hot bath treatment. ${ }^{22}$ ) 
Table I. Pyruvic Acid Contents in Organs of Normal Rats

\begin{tabular}{|c|c|c|c|c|c|c|c|c|}
\hline & \multicolumn{4}{|c|}{$\begin{array}{l}\text { Blood Collection by Cervical Blood } \\
\text { Vessel Incision without Anesthesia }\end{array}$} & \multicolumn{4}{|c|}{ Nembutal Anesthesia } \\
\hline & \multicolumn{2}{|c|}{$\begin{array}{l}\text { Quiet Cases when } \\
\text { Blood Collection }\end{array}$} & \multicolumn{2}{|c|}{$\begin{array}{l}\text { Struggled Cases when } \\
\text { Blood Collection }\end{array}$} & \multicolumn{2}{|c|}{$\begin{array}{l}\text { Blood Collection by } \\
\text { Cervical Blood Vessel } \\
\text { Incision }\end{array}$} & \multicolumn{2}{|c|}{$\begin{array}{l}\text { Blood Collection from } \\
\text { Abdominal Vein }\end{array}$} \\
\hline & Cases & $\begin{array}{l}\text { Pyruvic } \\
\text { Acid }\end{array}$ & Cases & Pyruvic Acid & Cases & Pyruvic Acid & Cases & Pyruvic Acid \\
\hline Blood & 18 & $\begin{array}{l}0.90-1.70 \\
(1.34)\end{array}$ & 11 & $\begin{array}{l}1.62-2.70 \\
(2.10)\end{array}$ & 21 & $\begin{array}{l}1.20-1.90 \\
(1.55)\end{array}$ & 7 & $\begin{array}{l}1.10-2.20 \\
(1.60)\end{array}$ \\
\hline $\begin{array}{l}\text { Heart } \\
\text { Muscle }\end{array}$ & 18 & $\begin{array}{l}0.32-0.83 \\
\quad(0.62)\end{array}$ & 11 & $\begin{array}{l}0.64-1.30 \\
(0.85)\end{array}$ & 20 & $\begin{array}{l}0.38-0.93 \\
(0.68)\end{array}$ & 6 & $\begin{array}{l}0.27-0.54 \\
(0.35)\end{array}$ \\
\hline Kidney & 16 & $\begin{array}{l}0.34-1.01 \\
\quad(0.76)\end{array}$ & 8 & $\begin{array}{l}0.65-1.30 \\
(0.88)\end{array}$ & 19 & $\begin{array}{c}0.43-1.27 \\
(0.88)\end{array}$ & 6 & $\begin{array}{l}0.43-0.93 \\
(0.61)\end{array}$ \\
\hline Brain & 8 & $\begin{array}{l}0.51-1.18 \\
(0.94)\end{array}$ & 7 & $\begin{array}{l}0.65-1.55 \\
(1.10)\end{array}$ & 15 & $\begin{array}{l}0.65-1.37 \\
(1.13)^{-}\end{array}$ & 5 & $\begin{array}{l}0.58-1.01 \\
(0.78)\end{array}$ \\
\hline
\end{tabular}

The figures in parentheses show mean values.

tion without anesthesia, mean py contents of blood, heart muscle, kidney and brain were $1.34,0.62,0.76$ and 0.94 respectively. In cases in which rats struggled at the time of blood collection, py contents in each of them elevated, especially in blood.

In anesthetized rats* in which blood was collected by cervical blood vessel incision, blood and brain py contents were slightly higher than unanesthetized quiet rats. In cases in which blood was collected from abdominal vein by laparotomy, blood py contents were slightly high, but py contents in heart muscle, kidney and brain were adversely slightly low (Table I).

2) Py contents in organs of control pair fed rats: Control pair fed rats of 5 weeks were used and blood was collected by cervical blood vessel incision without anesthesia. As can be seen in Fig. 1, compared to normal rats, blood py contents were almost same, myocardial py contents were of slightly high tendency, and kidney and brain py contents were of slightly low tendency.

3) Py contents in organs of thiamine deficient rats: Thiamine deficient rats of 5-6 weeks were used and blood was collected by cervical blood vessel incision without anesthesia. As can be seen in Fig. 1, py contents of thiamine deficient rats were high as a whole, especially so in blood and heart muscle.

To investigate the relationship between py contents and thiamine deficient symptoms, exceptional cases in which typical thiamine deficient symptoms did not appear in spite of thiamine deficient feedings were collected. As can be seen in Table II, blood py contents increased slightly to $2.40-2.70$, but organ

* Blood was collected $10 \mathrm{~min}$, after intra-peritoneal injection of $3 \mathrm{mg} . / 100 \mathrm{Gm}$. of pentobarbital sodium. 


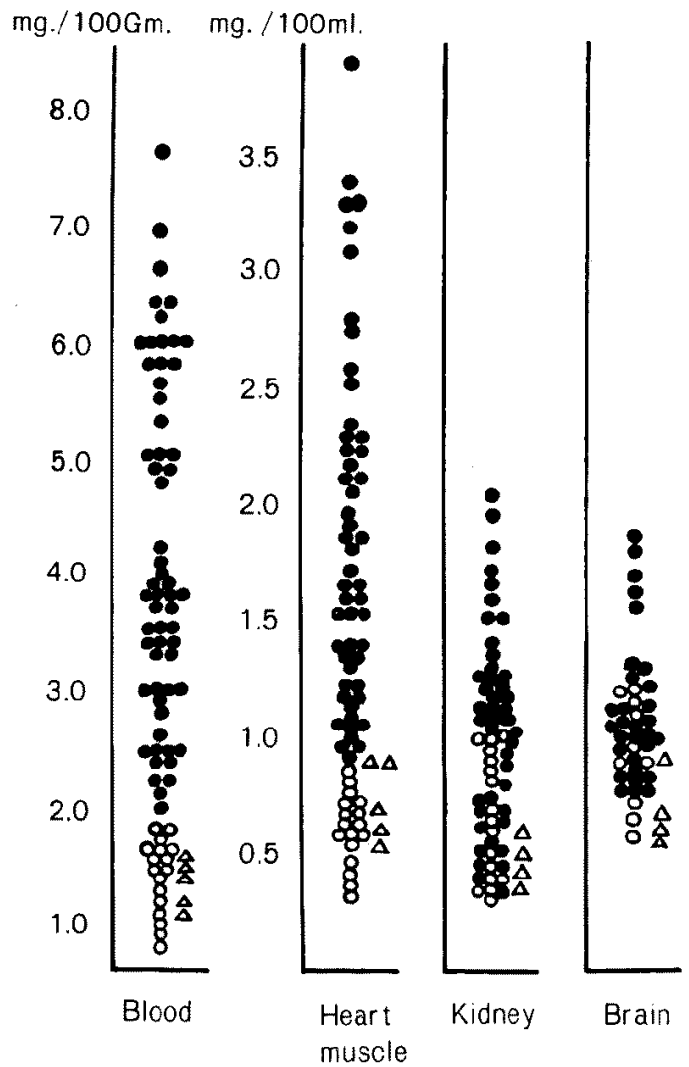

Fig. 1. Pyruvic acid contents in organs of thiamine deficient, control pair fed and normal rats.

- Thiamine deficient rats

$\triangle$ Control pair fed rats

O Normal rats

Table II. Pyruvic Acid Contents in Organs of Light Cases of Thiamine Deficient Symptoms

\begin{tabular}{|c|c|c|c|c|c|c|c|c|}
\hline \multirow{2}{*}{$\begin{array}{c}\text { Thiamine } \\
\text { Deficient } \\
\text { Days }\end{array}$} & \multirow{2}{*}{$\begin{array}{l}\text { Body } \\
\text { Weight }\end{array}$} & \multirow{2}{*}{$\begin{array}{c}\text { General } \\
\text { Symptoms }\end{array}$} & \multirow{2}{*}{$\begin{array}{l}\text { Heart } \\
\text { Weight } \\
\text { mg./100 } \\
\text { Gm. }\end{array}$} & \multirow{2}{*}{$\begin{array}{c}\text { Electrocardio- } \\
\text { graphic } \\
\text { Findings }\end{array}$} & \multicolumn{4}{|c|}{ Pyruvic Acid } \\
\hline & & & & & Blood & $\begin{array}{l}\text { Heart } \\
\text { Muscle }\end{array}$ & Kidney & Brain \\
\hline 34 & 106.0 & $\begin{array}{l}\text { Slight } \\
\text { paralysis? }\end{array}$ & 486 & $\begin{array}{l}\text { Heart rate } 486 / \mathrm{min} . \\
\text { normal axis }\end{array}$ & 2.60 & 0.68 & & 1.10 \\
\hline 34 & 121.0 & Healthy & 481 & $\begin{array}{l}\text { Heart rate } 406 / \mathrm{min} . \\
\text { normal axis }\end{array}$ & 2.50 & 0.69 & & 1.06 \\
\hline 41 & 67.0 & Anorexia & 515 & $\begin{array}{l}\text { Heart rate } 314 / \mathrm{min} . \\
\text { normal axis }\end{array}$ & 2.40 & 0.83 & 0.32 & \\
\hline 42 & 80.5 & Anorexia & 416 & $\begin{array}{l}\text { Heart rate } 374 / \mathrm{min} \text {, } \\
\text { normal axis }\end{array}$ & 2.70 & 0.45 & 0.31 & 0.66 \\
\hline
\end{tabular}


py contents remained within normal range. In other words, it was found that py contents were low in cases in which thiamine deficient symptoms were lacking.

Rats were divided according to kinds of thiamine deficient symptoms such as cardiac lesions (cardiac hypertrophy, bradycardia, arrhythmia and electrocardiographic abnormalities) or neuroparalysis. As can be seen in Table III, py contents in blood and heart muscle were markedly high in cardiac lesion groups and brain py contents were highest in groups with normal heart but with neuroparalysis. Py ratio between heart muscle and blood (this can be taken as a reciprocal of py clearance from heart muscle to blood or as py uptake from blood to heart muscle) was lowest in cardiac lesion groups but was highest in normal heart groups.

From the above, as it was found that there is a relationship between py contents in blood and heart muscle and cardiac lesions, further investigation on this point was carried out.

Fig. 2 is a study on the relationship between py contents in blood and

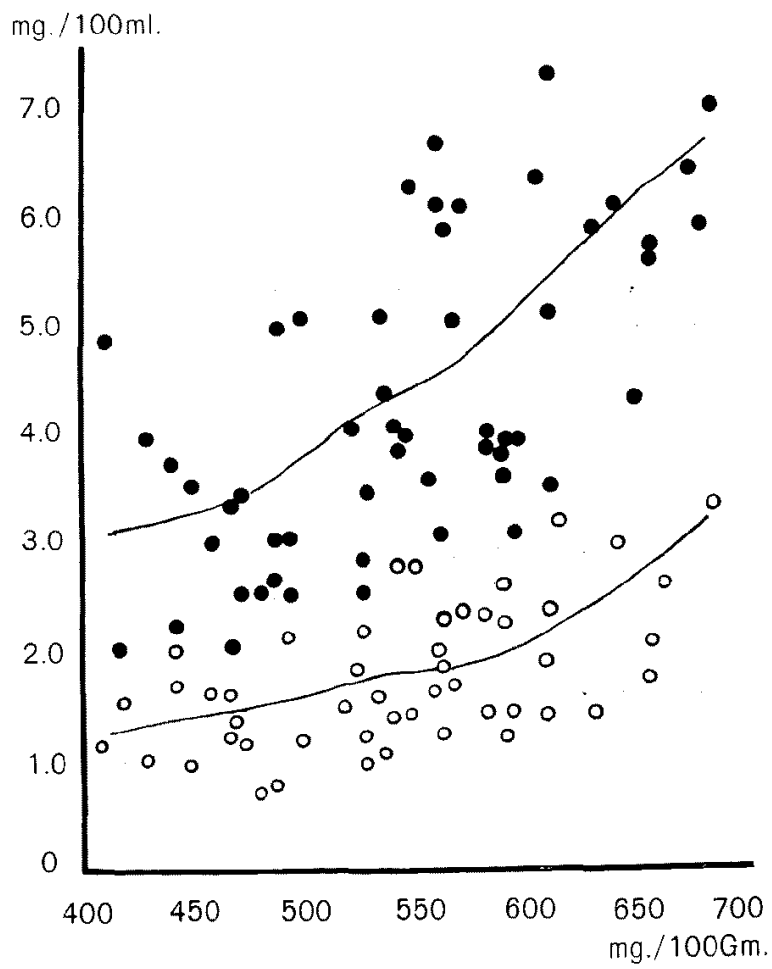

Fig. 2. Relationship between blood and myocardial pyruvic acid contents and heart weight.

- Blood pyruvic acid

Myocardial pyruvic acid 
Vol. 12
No. 5

THIAMINE DEFIGIENT CARDIAC LESION

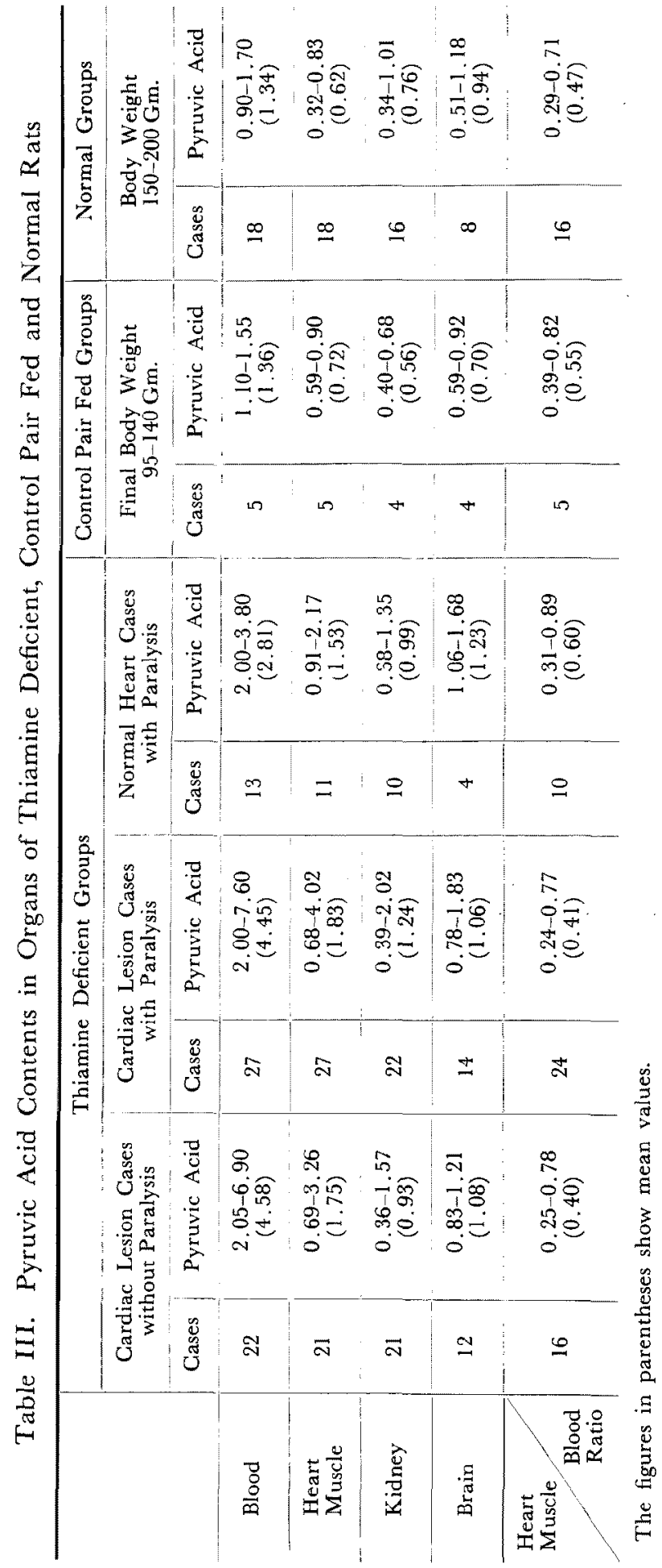




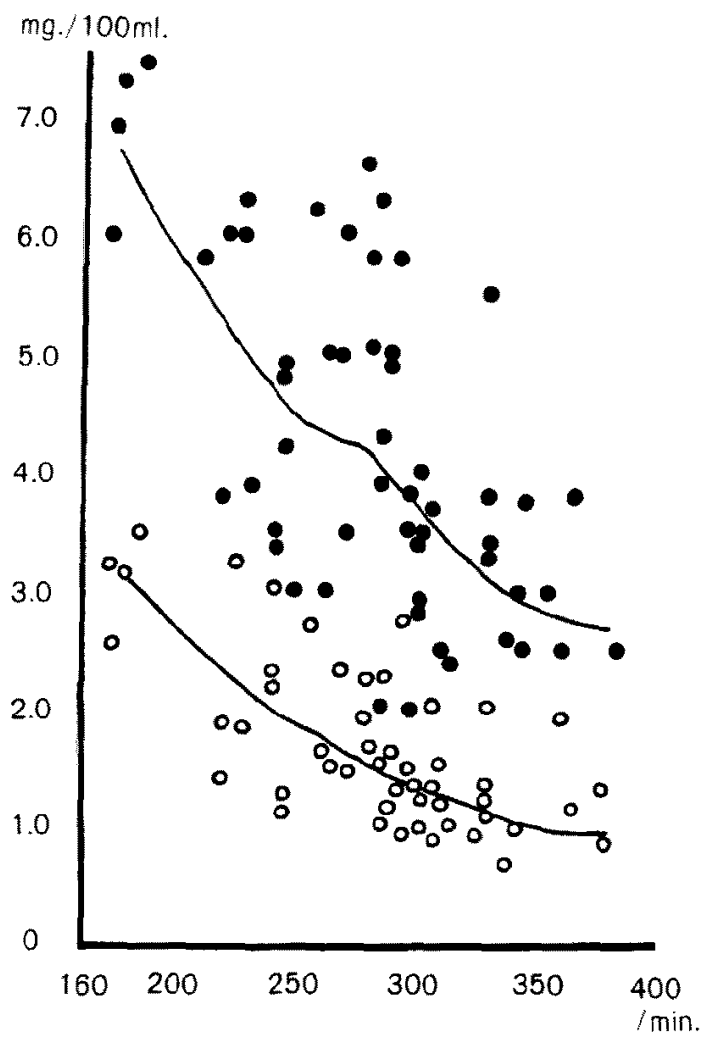

Fig. 3. Relationship between blood and myocardial pyruvic acid contents and heart rate.

- Blood pyruvic acid

Myocardial pyruvic acid

Table IV. Pyruvic Acid Contents in Blood and Heart Muscle and ST, T Abnormalities

\begin{tabular}{|c|c|c|c|c|c|}
\hline & & \multicolumn{2}{|c|}{ Blood } & \multicolumn{2}{|c|}{ Heart Muscle } \\
\hline & & Cases & Pyruvic Acid & Cases & Pyruvic Acid \\
\hline \multirow{2}{*}{ ST } & Elevation & 5 & $\begin{array}{l}3.40-7.60 \\
(4.84)\end{array}$ & 4 & $\begin{array}{l}1.52-3.16 \\
(2.26)\end{array}$ \\
\hline & Depression & 7 & $\begin{array}{l}3.00-7.00 \\
(4.78)\end{array}$ & 6 & $\begin{array}{l}0.94-2.35 \\
(1.35)\end{array}$ \\
\hline \multirow{2}{*}{$\mathrm{T}$} & Elevation & 4 & $\begin{array}{l}3.00-5.80 \\
(4.28)\end{array}$ & 4 & $\begin{array}{l}1.04-2.29 \\
(1.57)\end{array}$ \\
\hline & $\begin{array}{l}\text { Depression and } \\
\text { Flat }\end{array}$ & 28 & $\begin{array}{c}2.05-6.30 \\
(4.19)\end{array}$ & 27 & $\begin{array}{l}0.79-2.55 \\
(1.45)\end{array}$ \\
\hline
\end{tabular}

The figures in parentheses show mean values. 


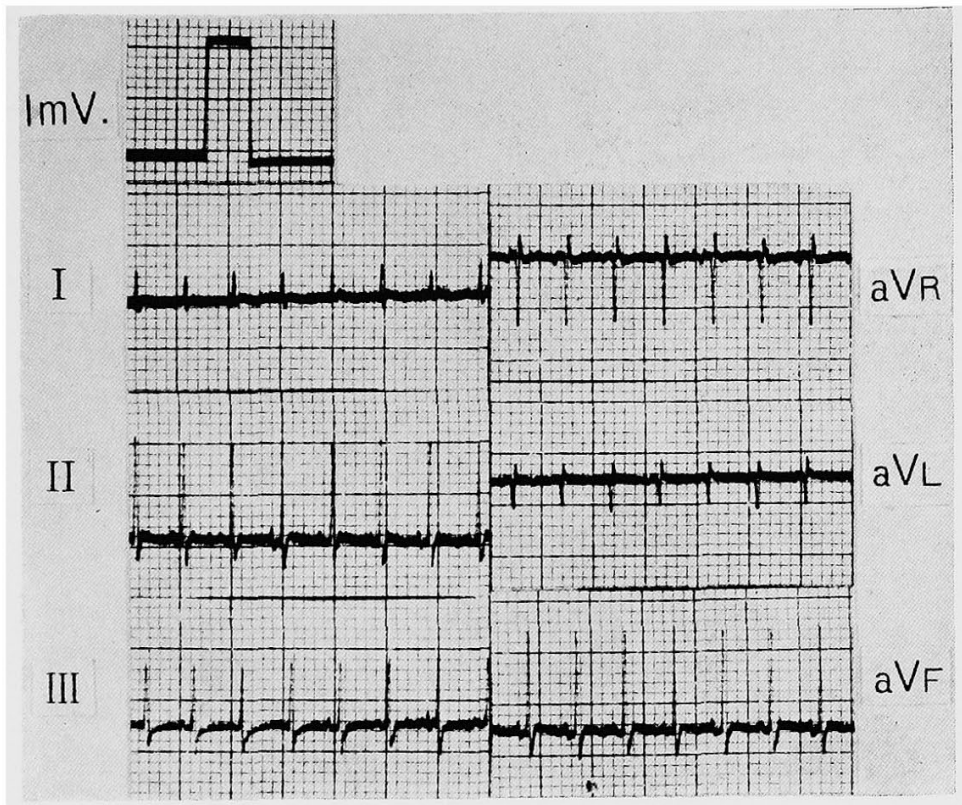

Fig. 4. No. 14 rat, thiamine deficient 32 days, $64.5 \mathrm{Gm}$., heart weight $558 \mathrm{mg} . / 100 \mathrm{Gm}$., heart rate $310 / \mathrm{min}$., pyruvic acid contents; blood 3.80, heart muscle 1.53 , kidney 0.87 , brain 1.01 .

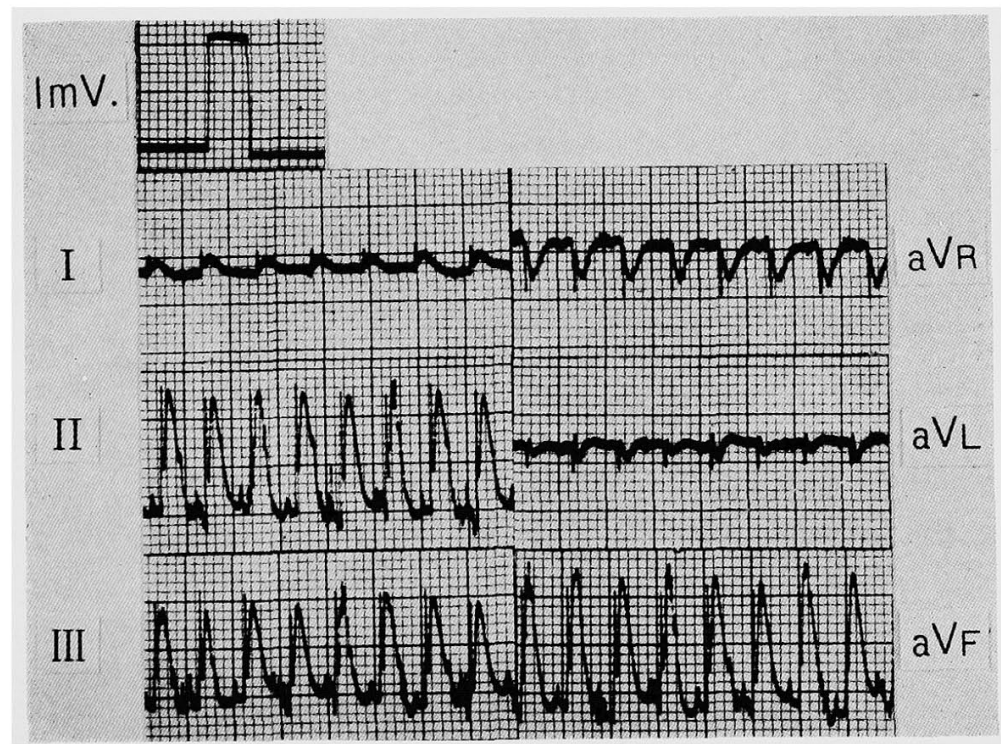

Fig. 5. No. 62 rat, thiamine deficient 35 days, $66 \mathrm{Gm}$., heart weight $630 \mathrm{mg} . / 100 \mathrm{Gm}$., heart rate $314-270 / \mathrm{min}$., pyruvic acid contents; blood 5.80, heart muscle 1.32 , kidney 0.89 . 


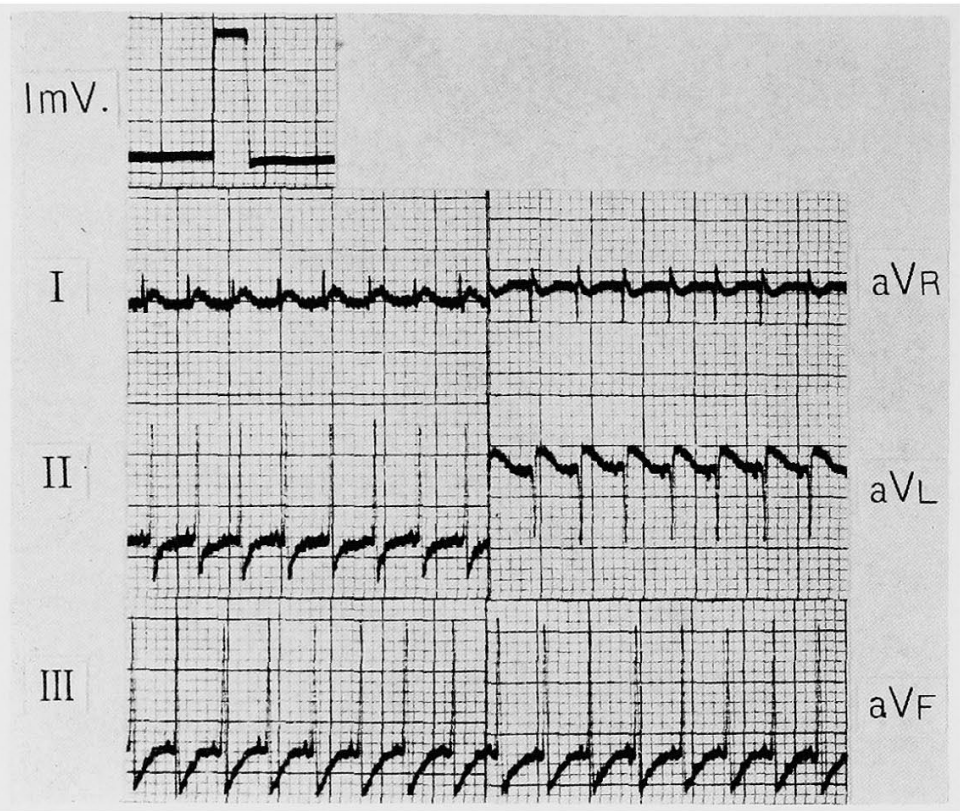

Fig. 6. No. 17 rat, thiamine deficient 33 days, $67.5 \mathrm{Gm}$., heart weight $594 \mathrm{mg} . / 100 \mathrm{Gm}$., heart rate $330 / \mathrm{min}$., pyruvic acid contents; blood 3.80 , heart muscle 1.37 , kidney 0.56 , brain 1.21 .

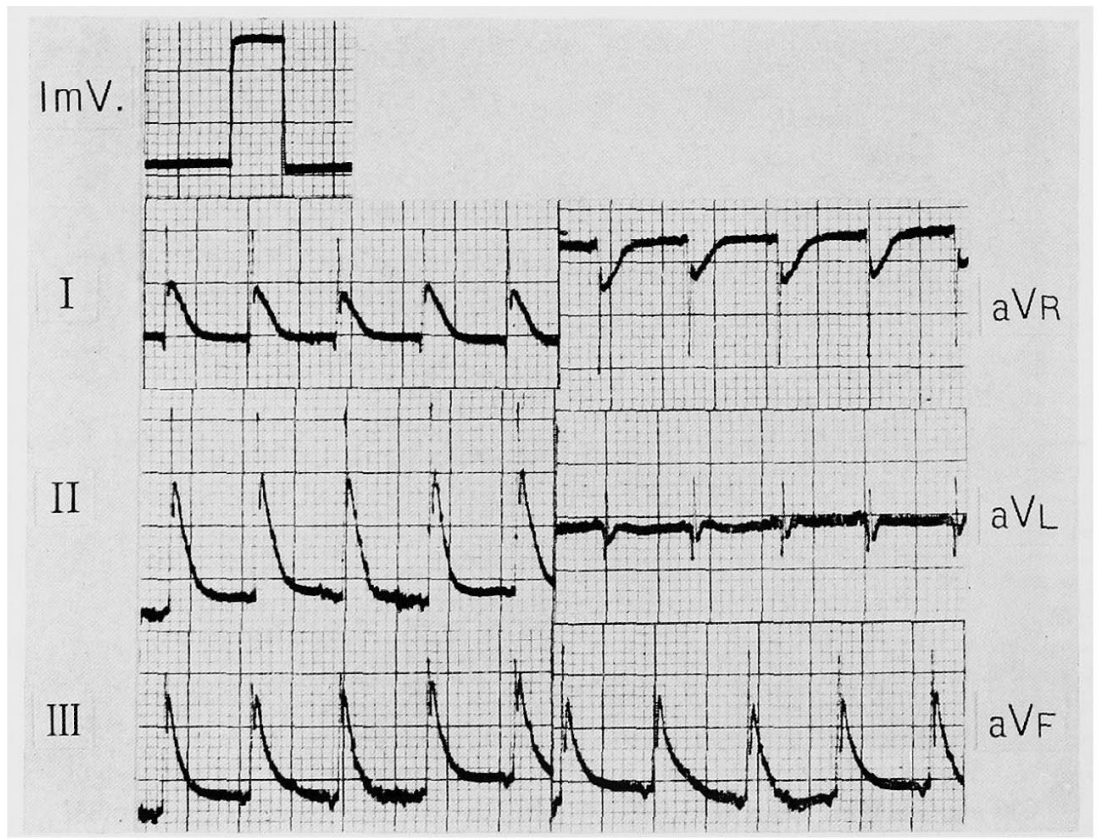

Fig. 7. No. 30 rat, thiamine deficient 36 days, $51.5 \mathrm{Gm}$, heart weight $614 \mathrm{mg} .100 \mathrm{Gm}$., heart rate $176 / \mathrm{min}$., pyruvic acid contents; blood 7.60, heart muscle 3.16 , kidney 1.05 , brain 1.38 . 
Table V. Pyruvic Acid Contents in Organs of Rats at Thiamine Deficient Final Stage

\begin{tabular}{|c|c|c|c|c|c|c|c|c|}
\hline \multirow{2}{*}{$\begin{array}{c}\text { Thiamine } \\
\text { Deficient } \\
\text { Days }\end{array}$} & \multirow{2}{*}{$\begin{array}{c}\text { Body } \\
\text { Weight }\end{array}$} & \multirow{2}{*}{$\begin{array}{c}\text { General } \\
\text { Symptoms }\end{array}$} & \multirow{2}{*}{$\begin{array}{l}\text { Heart } \\
\text { Weight } \\
\text { mg./100 } \\
\text { Gm. }\end{array}$} & \multirow{2}{*}{$\begin{array}{l}\text { Electrocardio- } \\
\text { graphic } \\
\text { Findings }\end{array}$} & \multicolumn{4}{|c|}{ Pyruvic Acid } \\
\hline & & & & & Blood & $\begin{array}{l}\text { Heart } \\
\text { Muscle }\end{array}$ & Kidney & Brain \\
\hline 37 & 85.5 & $\begin{array}{l}\text { Paralysis, } \\
\text { Emacia- } \\
\text { tion }\end{array}$ & 477 & $\begin{array}{l}\text { Heart rate } 142 / \mathrm{min}, \\
\text { A-V rhythm, right } \\
\text { axis, low voltage, } \\
\text { QRS prolongation }\end{array}$ & 6.00 & 2.57 & 3.14 & 1.43 \\
\hline 27 & 45.5 & $\begin{array}{l}\text { Moribund } \\
\text { condition, } \\
\text { Hypo- } \\
\text { thermia }\end{array}$ & 742 & $\begin{array}{l}\text { Heart rate } 126 / \mathrm{min} . \\
\text { A-V rhythm, } \\
\text { normal axis }\end{array}$ & 3.40 & 2.96 & 0.77 & 0.61 \\
\hline 39 & 80.0 & $\begin{array}{l}\text { Moribund } \\
\text { condition, } \\
\text { Hypo- } \\
\text { thermia }\end{array}$ & 457 & $\begin{array}{l}\text { Impossible to } \\
\text { record }\end{array}$ & 4.00 & 1.50 & 1.23 & 0.91 \\
\hline 33 & 70.0 & $\begin{array}{l}\text { Moribund } \\
\text { condition, } \\
\text { Hypo- } \\
\text { thermia }\end{array}$ & 629 & $\begin{array}{l}\text { Heart rate } 180-166 \text { / } \\
\text { min., A-V block, } \\
\text { normal axis, } \mathrm{T}_{\mathrm{III}} \\
\text { negative }\end{array}$ & 5.50 & 1.14 & 1.10 & \\
\hline 37 & 65.0 & $\begin{array}{l}\text { Moribund } \\
\text { condition }\end{array}$ & 397 & $\begin{array}{l}\text { Heart rate } 190-174 / \\
\text { min., A-V block, } \\
\text { supraventricular } \\
\text { premature beat, } \\
\text { right axis, } T \text { wave } \\
\text { fiat }\end{array}$ & 3.00 & 1.55 & 0.32 & 0.44 \\
\hline
\end{tabular}

heart muscle and cardiac hypertrophy. It can be seen that the higher the py contents in blood and heart muscle, the greater the cardiac hypertrophy.

Fig. 3 is a study on the relationship between py contents in blood and heart muscle and heart rate. It can be seen that the higher the py contents in blood and heart muscle, the severer the bradycardia.

Table IV is a study on the relation between py contents in blood and heart muscle and ST, T abnormalities in electrocardiograms. The most conspicuous findings were that myocardial py contents were markedly high in ST elevation groups but were lowest in ST depressions groups. Blood py contents in ST change groups were of slightly higher tendency than those in $\mathrm{T}$ change groups. Between $\mathrm{T}$ elevation groups and $\mathrm{T}$ depression groups, there were no significant differences in blood and myocardial py contents.

The following show typical examples of electrocardiographic abnormalities. Fig. 4 is a $T$ flat case and shows moderate increase of py contents such as blood 3.80 and heart muscle 1.53. Fig. 5 is a marked T elevation case in which py contents in blood and heart muscle are 5.80 and 1.32 respectively. Fig. 6 is a ST depression case and shows moderate py increase such as blood 3.80 and heart muscle 1.37. Fig. 7 is a ST elevation case and shows marked py increase 
such as blood 7.60 and heart muscle 3.16 .

Next are studies on changes of py contents in thiamine deficient last stage. Table $\mathrm{V}$ is a summarization of thiamine deficient last stage cases. Blood py contents showed quite a variation and organ py contents showed no definite tendency such as marked increase, slight increase, or decrease. In thiamine deficient last stage, electrocardiograms also show various changes-agonal changes-in which a definite explanation is difficult. The above variations of py contents also could be interpreted as a confusion of py metabolism at the transitional stage to death.

\section{Discussion}

For determination of py, hydrazone method or enzymatic method is now being used. The latter method is somewhat superior on the point of specificity but Friedemann-Haugen's method is also useful. ${ }^{12)}$ What is more important than the determination method is the collection method of the samples. ${ }^{14}$ As stated above, py contents vary greatly depending on the struggling of animals and anesthesia at the time of blood collection. Accordingly, strict condition for collection of samples is the most important factor in py determination experiments. In this experiment, blood was collected by cervical blood vessel incision without anesthesia to exclude the influence of anesthesia. In collected blood, arterial and venous blood are naturally mixed and this was fully taken in account when the results were considered.

For a long time it has been known that blood py increases when thiamine is deficient, but changes of organ py contents at that time has not been elucidated. Furthermore, concerning the correlation between py contents and thiamine deficient symptoms there are conflicting views and as yet there is no definite conclusion.

From the results that blood and organ py contents elevated in thiamine deficient groups but did not in control pair fed groups, it became known that there was no influence of starvation to py increase by thiamine deficiency.

It also became known that there was a correlation between thiamine deficient symptoms and py increase from the results that there were hardly any py increase in cases in which thiamine deficient symptoms were lacking, whereas py increased in cases with obvious symptoms.

Up to now there has been an opinion that py accumulation is not the cause of thiamine deficient cardiac lesions because py loading showed no definite influence on thiamine deficient cardiac lesions (on the other hand the author has observed the worsening of bradycardia and electrocardiographic changes by a single and a serial injections of $\mathrm{py}^{15)}$ ). However, it is said that 
in thiamine deficient cardiac muscle, py utilization is disturbed and its uptake from blood stream is not only depressed but py produced in heart muscle is poured in blood in spite of hyperpyruvemia. ${ }^{16)}$ In this experiment also the depression of py ratio between heart muscle and blood was observed. Accordingly, there is little possibility that loaded py directly effect heart muscle even administered in large doses.

Results of the present experiments-myocardial and blood py contents were markedly high in cardiac lesion groups, myocardial and blood py contents elevated parallel with severity of bradycardia and cardiac hypertrophy, and myocardial py contents were especially high in ST elevation cases-indicate py accumulation in heart muscle and blood, especially in heart muscle, is the strong factor of thiamine deficient cardiac lesions.

From recent electron-microscopic studies, ${ }^{10), 17)}$ it is also considered that accumulated py and lactate in heart muscle cause an increase of osmotic pressure in the mitochondria and rapid inflow of large volume of liquid into them, and results often in their rupture.

\section{REFERENGES}

1. Peters, R. A. and Thompson, R. H. S.: Biochem. J. 28: 916, 1934.

2. Thompson, R.H.S. and Johnson, R. H.: Biochem. J. 29: 694, 1935.

3. Peters, R. A.: Lancet 1: 1161, 1936.

4. Lu, G. D.: Biochem. J. 33: 774, 1939.

5. Platt, B. S. and Lu, G. D.: Biochem. J. 33: 1525, 1939.

6. Yoshitoshi, Y., Shibata, N., and Yamashita, S.: Jap. Heart J. 2: 42, 1961.

7. Yoshitoshi, Y., Shibata, N., and Yamashita, S.: Jap. Heart J. 3: 342, 1962.

8. Yoshitoshi, Y., Shibata, N., and Yamashita, S.: Jap. Heart J. 5: 150, 1964.

9. Yamashita, S.: Jap. Heart J. 12: 242, 1971.

10. Yamashita, S.: Jap. Heart J. 12: 354, 1971.

11. Yamashita, S.: Shinzo 2: 141, 1970 (in Japanese).

12. Yoshitoshi, Y., Shibata, N., and Yamashita, S.: Vitamin 34: 116, 1966 (in Japanese).

13. Friedemann, T. E. and Haugen, G. E.: J. Biol. Chem. 147: 415, 1943.

14. Friedemann, T. E. and Haugen, G. E.: J. Biol. Chem. 144: 67, 1942.

15. Yamashita, S.: Unpublished observation.

16. Randles, F. S., Himwich, W. A., Homburger, E., and Himwich, H. E.: Am. Heart J. 33: $341,1947$.

17. Suzuki, T.: Tohoku J. Exp. Med. 91 : 249, 1967. 